\title{
Academic productivity of neurosurgery residents in Europe
}

\section{Bedjan Behmanesh $^{1}$}

Received: 11 December 2019 / Accepted: 12 December 2019 / Published online: 21 December 2019

(C) Springer-Verlag GmbH Austria, part of Springer Nature 2019

First of all, we would like to thank Dr. Adomas Bunevicius for the nice suggestions and issues.

As already mentioned and noticed, there are some significant differences of the publication productivity, h-index, and research activity between neurosurgical residents in Germany and USA.

In our opinion, there are few reasons regarding the transatlantic difference of academic productivity.

The first step finding reasons therefore might be the application modus before starting residency. As Khan et al. described, the total number of publications differed from the hindex ${ }^{\mathrm{R}}$ achieved during the residency (6.3/9.2) [2]. That means that a significant number of publications were published before admitting the residency program and that the publication productivity starts prior to medical practice.

Similar to our findings, Wilkes et al. confirmed the positive correlation of possessing an advanced research degree and greater academic productivity [4]. Comparing the websites of US and German departments, we found a significant higher number of US residents with a $\mathrm{PhD}$ degree than German residents. Not only in neurosurgery but also in other disciplines, such as urology and orthopedic surgery, the evaluation of publication productivity showed that there was a highly significant positive correlation among programs that have protected research time, research funding, medical editing support, and travel support. Taken together, these pieces help create a supportive environment, coupled with positive sustained mentorship, that values resident research $[1,2,5]$. In our very first analysis evaluating the research activity, we could not find any further information about protected research programs in Germany. We further could show that compared to the USA, the number of female residents is significantly higher and reflects the aspect of the female

This article is part of the Topical Collection on Neurosurgery Training

Bedjan Behmanesh

bedjan.behmanesh@gmail.com

1 Department of Neurosurgery, Goethe University Hospital, Frankfurt am Main, Germany overweight, which also could be detected in German universities. According to previous published data, we could also show that a higher h-index is associated with male gender among neurosurgical residents $[2,3,6]$. Despite lack of correlation between the number of physicians, department size, number of attending physicians, and residents' academic output, we cannot confirm or deny the total number of resident publications and the academic output of the faculty and attending physicians. This aspect needs to be evaluated in a further step of analyzing the academic output of German neurosurgeons. Our published data should be an initial step providing data about research activity and academic output of neurosurgeons in Germany. Unfortunately, we did not investigate any ranking among German neurosurgical resident programs. Despite some limitations, we tried to provide helpful data of publication activity among neurosurgical residents and encourage colleagues in Europe to provide their data.

\section{References}

1. Finkelstein JB, Van Batavia JP, Rosoff JS (2015) The difference a year can make: academic productivity of residents in 5 vs 6 -year urology programs. Urology 86(2):220-222

2. Khan NR, Saad H, Oravec CS et al (2018) An analysis of publication productivity during residency for 1506 neurosurgical residents and 117 residency departments in North America. Neurosurgery. https:// doi.org/10.1093/neuros/nyy217

3. Kilinc F, Gessler F, Dubinski D, Won S-Y, Quick-Weller J, Seifert V, Behmanesh B (2019) Academic output of German neurosurgical residents in 35 academic neurosurgery residency programs. Acta Neurochir 161(10):1969-1974

4. Wilkes FA, Akram H, Hyam JA, Kitchen ND, Hariz MI, Zrinzo L (2015) Publication productivity of neurosurgeons in Great Britain and Ireland. J Neurosurg 122(4):948-954

5. Williams BR, Agel JA, Van Heest AE (2017) Protected time for research during orthopaedic residency correlates with an increased number of resident publications. J Bone Joint Surg Am 99(13):e73

6. Yang G, Villalta JD, Weiss DA, Carroll PR, Breyer BN (2012) Gender differences in academic productivity and academic career choice among urology residents. J Urol 188(4):1286-1290

Publisher's note Springer Nature remains neutral with regard to jurisdictional claims in published maps and institutional affiliations. 